\title{
RELAÇÃO DE HIPERTENSÃO, DIABETES E OBESIDADE EM IDOSAS DO UCS SÊNIOR COM NUTRIENTES E ANTROPOMETRIA
}

Valéria Cristina Artico; Universidade de Caxias do Sul (UCS); vcartico@ucs.br Ricardo Reichenbach; Universidade de Caxias do Sul (UCS); rreichenbach@ucs.br Josiane Siviero; Universidade de Caxias do Sul (UCS); jsiviero@ucs.br

\section{RESUMO}

Introdução: A prevalência de diabetes mellitus tipo 2 (DM2), hipertensão arterial sistêmica (HAS) e obesidade em idosas é significativa no Brasil. Uma mudança de estilo de vida, com adequação dietética e controle do peso corporal, podem ser importantes aliados no manejo dessas doenças. Objetivo: Avaliar a prevalência de DM2, HAS e obesidade em idosas do programa de extensão UCS Sênior e a relação com nutrientes e antropometria. Metodologia: Estudo transversal retrospectivo e descritivo com 130 idosas ( $\geq 60$ anos) do Programa UCS Sênior. As variáveis foram obtidas através de entrevistas e avaliação antropométrica. Os dados foram analisados de acordo com o preconizado pelas Diretrizes Brasileiras referentes às patologias já mencionadas. Utilizou-se o Excel 14.0 para análise estatística. Resultados: As idosas hipertensas da amostra consomem 5\% menos sódio que as não hipertensas. Referente aos macronutrientes, $54 \%$ consomem o percentual de gordura preconizado, $60 \%$ o de carboidrato e $40 \%$ o recomendado para proteínas. Entre as diabéticas, há deficiência especialmente no consumo de proteínas. Quanto às obesas e o consumo de macronutrientes, a maioria apresenta um déficit na quantidade. Conclusão: As idosas hipertensas frequentadoras do Programa UCS Sênior demonstram-se orientadas em relação ao consumo de sódio abaixo dos 2 gramas/dia. No entanto, em todas as condições patológicas, observa-se uma má aderência quanto ao consumo adequado de macronutrientes. Com tais dados, é possível, direcionar uma atividade de orientação no programa UCS Sênior pautada sobre os principais déficits nutricionais, sendo pontual na correção de determinadas práticas alimentares.

Palavras-chave: Idoso; Nutrientes; Doença Crônica. 